\title{
APLIKASI SISTEM INVENTORY BAHAN PENDUKUNG BERBASIS WEB UNTUK PT. TATALOGAM LESTARI
}

\author{
Rendy Winata \\ President University \\ rendywinata@gmail.com
}

\author{
Rusdianto Roestam \\ President University \\ rusdianto@president.ac.id
}

\begin{abstract}
Abstrak - Pengendalian stock terhadap bahan pendukung ini sangat penting agar proses produksi bisa berjalan dengan baik. Pembuatan sistem inventory ini merupakan bagian dari proses pengendalian stock. Metodologi pengembangan aplikasi inventory bahan pendukung mengadopsi metode Feature Driven Development (FDD) mulai dari pengembangan model sampai pada membangun sistem berdasarkan feature yang telah ditentukan. Aplikasi yang dibangin telah memberikan effisiensi baik dalam hal pengelolaan laporan stock barang maupun pengontrolan dan pemesanan pembelian barang.
\end{abstract}

\section{Latar Belakang}

PT. Tatalogam Lestari adalah perusahaan yang bergerak dibidang baja ringan. Pada proses produksi baja ringan ada beberapa tahapan yang dilakukan dari bahan mentah sampai bahan jadi. Pertama adalah bahan mentah berupa coil di Slitting terlebih dahulu menjadi beberapa bagian sesuai dengan ukuran yang diperlukan. Kemudian coil yang telah di Slitting sesuai dengan ukuran yang diperlukan diproduksi pada mesin Roll Forming, pada tahap ini produk diberikan penamaan produk sesuai dengan produk yang dihasilkan. Kemudian produk dipacking dan diserahkan kepada bagian warehouse.

Pada setiap produk yang dihasilkan harus diberikan penamaan agar produk tersebut memiliki identitas pada saat dijual. Jika tidak ada penamaan pada produk, maka produk tersebut tidak akan bisa dijual. Un -tuk melakukan penamaan pada produk diperlukan bahan pendukung salah satunya yaitu tinta. Jika stock tinta habis maka produk tidak bisa diberikan penamaan dan tidak bisa dijual. Tinta bisa habis karena tidak adanya stock kontrol yang mengatur ketersediaan bahan pendukung tinta.

Selain itu dalam pembuatan laporan juga masih membutuhkan waktu yang cukup lama karena penginputan dan pembuatan laporan masih dilakukan secara manual sehingga kemungkinan besar kesalahan data sangat mungkin terjadi baik double penginputan atau salah dalam penginputan data.

\section{Sistem Inventory}

Didalam suatu perusahaan, baik itu perusahaan perdagangan maupun perusahaan manufaktur pasti selalu mengandalkan persediaan (inventory). Persediaan sebagai kekayaan perusahaan, memiliki peranan penting dalam operasi bisnis. Dalam perusahaan manufaktur, persediaan dapat terdiri dari beberapa macam seperti berikut :
a. Bahan Baku.
b. Bahan Pembantu.
c. Barang Dalam Proses.
d. Barang Jadi.
e. Persediaan Suku Cadang.

Menurut Schroeder (2000:4) yang mengatakan bahwa definisi persediaan atau inventory adalah stock bahan yang digunakan untuk memudahkan produksi atau untuk memuaskan permintaan pelanggan.

Dalam pembuatan persediaan pastinya ada tujuan yang ingin dicapai atau sesuatu yang ingin diketahui oleh pembuat persediaan tersebut. Menurut Anggarini (2007:163) yang mengutarakan bahwa tujuan kebijakan persediaan adalah untuk merencanakan tingkat optimal investasi persediaan dan mempertahankan tingkat optimal tersebut melalui persediaan.

Selain memiliki tujuan persediaan juga memiliki bebera fungsi yang dapat dipergunakan oleh orang yang memerlukanya. Menurut Tampubolon (2004:190) ada 3 fungsi persediaan yaitu :
a. Fungsi Decoupling
b. Fungsi Econimic Size
c. Fungsi Antisipasi 
Menurut Handoko (1999:334) berdasarkan bentuk fisiknya, persediaan dapat dibedakan menjadi beberapa jenis, yakni sebagai berikut :

a. Persediaan Bahan Mentah.

Artinya adalah persediaan barang berwujud, seperti besi, kayu, serta komponen-komponen lain yang digunakan dalam proses produksi.

b. Persediaan Komponen-Komponen Rakitan.

Artinya adalah persediaan barang-barang yang terdiri dari komponen-komponen yang diperoleh dari perusahaan lain secara langsung dapat dirakit menjadi suatu produk.

c. Persediaan Bahan Pembantu atau Penolong.

Artinya adalah persediaan barang-barang yang diperlukan dalam proses produksi, tetapi bukan merupakan bagian atau komponen barang jadi.

d. Persediaan Dalam Proses

Artinya adalah persediaan barang-barang yang merupakan keluaran dari tiap-tiap bagian dalam proses produksi atau telah diolah menjadi suatu bentuk, tetapi masih perlu diproses lebih lanjut menjadi barang jadi.

e. Persediaan Barang Jadi

Artinya adalah persediaan barang-barang yang telah selesai diproses atau diolah dalam pabrik dan siap dijual atau dikirim kepada pelanggan.

\section{Batasan Masalah}

Untuk memaksimalkan aplikasi yang akan dibuat, maka penulis memberikan batasan masalah untuk pembuatan aplikasi ini, diantaranya :

a. Aplikasi yang dibuat mencatat proses barang masuk dan barang keluar.

b. Aplikasi yang dibuat membantu dalam pembuatan laporan bahan pendukung.

c. Aplikasi yang dibuat dapat memunculkan grafik pemakaian dan pemasukan barang bahan pendukung.

d. Aplikasi yang dibuat dapat mengirim e-mail secara otomatis ketika barang sudah masuk dalam batasan minimum.

\section{Metode Pengembangan}

Metode pengembangan yang digunakan adalah Feature Driven Development yang terdiri dari 5 tahapan yaitu :
a. Develop an Overall Model
b. Build a Feature List
c. Plan by Features
d. Design by Feature dan
e. Build by Feature.

\section{Feature Yang Dihasilkan}

a. Tambah data barang.

Tambah data barang merupakan proses penambahan barang baru kedalam sistem yang dapat dilakukan oleh user dengan hak akses purchasing.

b. Tambah data satuan barang.

Tambah data satuan barang prosesnya sama seperti tambah data barang yaitu proses penambahan data kedalam sistem.

c. Input barang masuk dan barang keluar.

Setiap barang masuk dan barang keluar yang dilakukan dicatat dalam sistem melalui menu input barang masuk dan barang keluar ini. Menu ini hanya bisa diakses oleh user produksi saja.

d. Penarikan laporan barang masuk dan barang keluar.

Dari data barang masuk dan barang keluar yang sudah dicatat dalam sistem maka hasil inputan tersebut bisa ditarik melalui menu yang disediakan.

e. Stock barang.

Stock barang menampilkan data keseluruhan barang yang ada meliputi jumlah barang masuk, barang keluar dan sisa saldo akhir barang yang ada pada sistem.

f. Penarikan data ke format excel atau pdf

Penarikan laporan yang ada bisa ditarik dalam dua format yaitu excel dan pdf.

g. Grafik barang masuk dan barang keluar.

Dari data transaksi barang masuk dan barang keluar yang ada, anda bisa melihat grafik pemakaian dan penerimaan barang yang ada dengan periode per bulan.

\section{Metode Pengujian}

Metode pengujian yang dilakukan pada sistem aplikasi ini adalah metode blackbox testing. Black box testing adalah pengujian yang dilakukan hanya mengamati hasil eksekusi melalui data uji dan memeriksa fungsional dari perangkat lunak. Jadi dianalogikan seperti kita melihat suatu kotak hitam, kita hanya bisa melihat penampilan luarnya saja, tanpa tau ada apa dibalik bungkus hitam nya. Pengujian black box hanya mengevaluasi dari tampilan luarnya(interface nya), fungsionalitasnya tanpa mengetahui apa sesungguhnya yang terjadi dalam proses detilnya (hanya mengetahui input dan output). 


\section{Hasil Pengujian}

Berdasarkan pengujian yang telah dilakukan membuktikan bahwa sistem aplikasi dapat digunakan sesuai dengan yang diharapkan pada proses pengujian. Berdasarkan pengujian yang dilakukan sistem aplikasi dapat memeriksa akses login dan memberikan warning jika data yang dimasukkan tidak sesuai dengan yang diinginkan oleh sistem. Dengan hasil pengujian yang telah dilakukan bisa disimpulkan bahwa sistem aplikasi ini sudah siap digunakan dan dapat menghasilkan output yang diharapkan.

\section{Kesimpulan}

Setelah menganalisa dari permasalahan yang ada maka bisa diambil kesimpulan sebagai berikut :

1. Penerapan aplikasi ini telah berdampak pada effisiensi waktu dan tenaga sehingga user tidak perlu mencatat secara manual terhadap barang yang keluar dan masuk.

2. Pengelolaan laporan stock barang bisa dilakukan secara effisien tanpa banyak melibatkan tenaga operator.

3. Pemesanan pembelian barang bisa secara cepat dan tepat berdasarkan pada hasil proses transaksi pemanfaatan barang.

4. Pengontrolan barang dapat dilakukan secara effisien karena mekanisme pengontrolan ini telah diterapkan didalam sistem ini.

\section{Daftar Pustaka}

[1] Adisaputro, Anggarini. 2007. Anggaran Bisnis Analisa, Perencanaan, dan Pengendalian Laba. Penerbit UPP STIM YKPN: Yogyakarta.

[2] Amith Pulla, Feature Driven Development (FDD), a presentation, NJIT.

[3] Anton M. Meliono, Kamus Besar Bahasa Indonesia, Penerbit Balai Pustaka, Jakarta: 1990.

[4] Gordon B. Davis, Kerangka Dasar Sistem Informasi Manajemen Bagian 1, PT Pustaka Binamas Pressindo, Jakarta: 1991 .

[5] Handoko, T. Hani. 1999. Dasar-dasar Manajemen Produksi dan Operasi, Edisi 7. BPFE: Yogyakarta.

[6] Jogiyanto HM. 2005. Analisis \& Desain Sistem Informasi : Pendekatan Terstruktur Teori dan Praktek Aplikasi Bisnis. Yogyakarta. Andi.
[7] Pekka Abrahamsson and Juhani Warsta, Agile Software Development Methods Review and Analysis, Julkaisija-UtgivarePublisher, 2002.

[8] Rangkuti, F. 2004. Manajemen Persediaan Aplikasi di Bidang Bisnis. Penerbit Erlangga: Jakarta.

[9] Reid S. Calberg, Feature Driven Development, SE470, www.fivesticks.com/intoo/fdd.

[10] Roger, Schroeder. 2000. Pengembilan Keputusan Dalam Suatu Fungsi Operasi, Edisi Ketiga. Erlangga: Jakarta.

[11] Stephen R. Palmer dan John M. Felsing, Practical Guide to Feature Driven Development, Prentice Hall, 2001.

[12] Tata Sutabri, Sistem Informasi Manajemen, 2005, Yogyakarta, Andi.

[13] Tampubolon, 2004. Manajemen Operasional. Penerbit Ghalia Indonesia: Jakarta. 